\title{
Effect of Foot Reflexology and Olive Oil Foot Massageon Asthma
}

\section{Control}

\author{
Seemin Dashti ${ }^{1}$, Mehraban Shahmari ${ }^{2}$, Ahmad Mirzaaghazadeh $^{3} \&$ Mohammad Mirzaaghazadeh $^{4}$ \\ ${ }^{1}$ Faculty of Medical Sciences, Islamic Azad University of Ardabil, Ardabil, Iran \\ ${ }^{2}$ Imam Khomeini Hospital, Ardabil University of Medical Sciences, Ardabil, Iran \\ ${ }^{3}$ Faculty of Paramedical, Tabriz University of Medical Sciences, Tabriz, Iran \\ ${ }^{4}$ Faculty of Medical and Paramedical, Ardabil University of Medical Sciences, Ardabil, Iran \\ Correspondence: Mehraban Shahmari, Imam Khomeini Hospital, Ardabil University of Medical Sciences, \\ Ardabil, Iran, Shahid Jeddi Street, Ardabil, Iran. Tel: 98-453-325-1685. E-mail: mehrabanshahmari@yahoo.com
}

\author{
Received: December 31, 2015 Accepted: April 9, 2016 Online Published: April 29, 2016 \\ doi:10.5539/gjhs.v8n12p53 URL: http://dx.doi.org/10.5539/gjhs.v8n12p53
}

\begin{abstract}
Background: There are some non-invasive and affordable treatments for asthma with fewer side effects, such as reflexology and olive oil foot massage in complementary and alternative medicine. There is a lack of studies regarding the efficacy of olive oil foot massage and reflexology for asthma control. This study was done to investigate the effect of foot reflexology and olive oil foot massage on asthma control.

Methods: This randomized controlled clinical trial study was performed in 2013 on 45 adult patients suffered from asthma. Participants were divided into three groups (15 in each group): foot reflexology (R), olive oil foot massage $(\mathrm{O})$ and control $(\mathrm{C})$. The reflexology and olive oil foot massage were done by a massage therapist for ten sessions, three times a week for 15 minutes. Asthma control questionnaire (ACQ) was used to determine the adequacy of asthma control. Data were analyzed by SPSS 18. P-value $<0.05$ was considered statistically significant.
\end{abstract}

Results: Significant difference was seen in Asthma Control mean scores for both of reflexology and foot massage groups at the baseline and after the intervention $(\mathrm{p}<0.01)$. There was no significant difference between $\mathrm{R}$ and $\mathrm{O}$ groups in their asthma control mean scores at the end of the intervention.

Conclusion: The results showed that foot reflexology and olive oil foot massage could improve the asthma control. Further study is needed on the interaction of these two interventions, to compare them with the use of specific drug treatments, and to investigate the effect of olive oil absorption on asthma.

Keywords: asthma olive oil, foot massage, reflexology

\section{Introduction}

Asthma is a chronic inflammatory disease with high prevalence and mortality. According to the World Health Organization reports, there are more than 20000 asthma deaths in 2015 in Eastern Mediterranean regions, and also, asthma prevalence is expected to be doubled in 2020 (WHO, 2014; Masoli et al., 2004; Mathew et al., 2012). The results of studies in Iran shows that in average 5-7 percent of the population suffers from asthma. Asthma imposes numerous economic burdens on families and communities, so economic expenses due to asthma and its treatment are increasing. Moreover, expenditures burdened to asthmatic patients at the time of hospitalization, using drugs of asthma, loss of parents' jobs and absence of children from school are necessary for Community (Botting, 1997; Brygge et al., 2001).

Recently, complementary and alternative medicine (CAM) therapies are one of the strategies used along with conventional pharmacological therapies for many diseases, which have been effective in many cases; reflexology is a part of complementaryTherapies (Qamar et al., 2011). Foot reflexology is a massage, which uses finger pressure specific zones of the feet. Many nurses have added complementary and alternative medicine (CAM) treatments such as reflexology to their clinical practice (Botting, 1997). Reflexology is a well-known CAM treatment for asthma in Iran, and it is commonly well regarded (Brygge et al., 2001). Reflexology is easy to learn treatment for patients to incorporate them into their treatments to achieve better results for health. The effects of 
reflexology aren't related to their psychological impact; this form of treatment was tested on children, and its positive effects were achieved (Nekooee et al., 2008). Nakamaru et al. used functional MRIs to show that reflexological stimulation induced a somatosensory process. They stimulated three reflex areas on the foot corresponding to the eye, shoulder, and small intestine and used MRI with statistical analysis to show that reflexological stimulation of these foot reflex areas activated the somatosensory areas of the foot and the somatosensory areas for the eye, shoulder, and small intestine or neighboring body parts. They stated that neuroimaging could be used to examine the basis of reflexological effects (Nakamaru et al., 2008). Reflexotherapy is a complementary method that relaxes and reduces stress (Gunnarsdottir \& Jonsdottir, 2007).

Foot massage with olive oil is another low-cost traditional treatment without any side effects. Vegetable oil massages have been used to treat asthma (Liang, 2005) and are popular treatments among patients. Reznik et al. showed that $74 \%$ of participants who used CAM employed foot massage (Reznik et al., 2002). Olive oil has essential properties that inhibit cyclooxygenase enzyme (an inflammatory agent) (Sorcinelli, 1997; Beauchamp et al., 2005). Vegetable oil foot massage carried out by hand are usually applied to the meridian (path through which life-energy flows and is drawn up through the feet). The Meridian is a network of energy channels or electrical pathways covering the body that is similar to the zones that are traditionally known in reflexology. Meridians are used in acupuncture, and these energy lines are also found in reflexology. The meridian system has 100 meridians and connections. There are 12 standard meridians that are connected to one another by organs (Voner, 2003).

It can be assumed that rubbing an anti-inflammation agent such as olive oil into meridian of the foot could control airway inflammation in diseases such as asthma. There are numerous studies about different methods of asthma treatment, but data few studies have been done on the efficacy of olive oil foot massage and reflexology for asthma control. With attention to increased asthma prevalence as a common and chronic illness and its unpleasant outcomes, asthma control is important in the prevention of its complications among patients. In this study, we decided to examine whether these complementary therapies (reflexology and rub olive oil) could control asthma than routine medical treatments.

\section{Method}

This randomized controlled clinical trial was done on 45 female ( $>12$ years) who suffered from asthma. Asthma in patients was diagnosed based on the results of spirometry and classic signs by an assistant professor of pulmonary and critical care medicine. . This study was approved by the Ethical Committee of Tabriz University of Medical Sciences. A consent form was obtained from the participants of the study.

Patients were divided randomly into three study groups: foot reflexology $(\mathrm{n}=15)$, foot massage with unrefined olive oil $(\mathrm{n}=15)$ and; Control $(\mathrm{n}=15)$. All three groups continued their usual asthma medication that was prescribed by their physician prior starting the study. The treatment groups were advised of possible complications and the techniques were explained to the participants.

Exclusion criteria were pregnancy, injury or infection of the foot, the presence of cancer or blood infections, use of psychiatric drugs, fracture of the foot, leg edema, DVT, hospitalization during the study, diabetic neuropathy, and use of asthma treatments other than drugs prescribed by physicians. Participants were familiar with oil massage but had no familiarity with olive oil foot massage or reflexology or their relationships to asthma.

\subsection{Intervention}

The first treatment group carried out foot reflexology; the second group practiced foot massage with unrefined olive oil, and the control group received no intervention through study. All three groups continued their usual asthma medication which was prescribed by their physician prior starting the study.

Data collection tools for all groups was a demographic questionnaire containing questions about the participant's age, smoking history, family history of asthma and asthma control questionnaire (ACQ) (Amoli, 1998; Weiss et al., 1993). Asthma Control Questionnaire consists of six dimensions of waking us during the night (due to asthma attack) including the severity of symptoms in the morning, activity limit, shortness of breath, wheeze, the number inhales from short-acting bronchodilator. Answers are rated on a scale of 0-6. Zero specifies Better Control of Asthma and 6 Weak Control of Asthma.

The ACQ was formulated by Juniper et al. in 1999 and was revised in 2010 (Juniper et al., 2010). It contains five essential questions about asthma symptoms and one question about the use of a rescue bronchodilator. The authors of the ACQ generated a list of all symptoms used to assess control of asthma and sent it to 100 asthma clinicians from 18 countries who were members of guideline committees. They scored each symptom for importance for evaluating asthma control. From the 91 responses, the five highest-scoring symptoms were selected for the ACQ. All the questions in the questionnaire are equally weighted, and so the score is the mean of 
the responses to the six questions. Thus, the ACQ score is the mean of the six items and therefore between 0 (well controlled) and 6 (extremely poorly controlled).

The original version of the ACQ had seven questions with the last question relating to spirometry results. The ACQ was evaluated using Pearson's correlation coefficient, showed strong evaluative and discriminative properties and can be used with confidence to measure asthma control (Juniper et al., 1999). The short version of the ACQ showed no loss of validity or changes in interpretation and were usable for large clinical trials (Juniper et al., 2005). The internal correlation, reliability and stability of ACQ with the ICC index were verified (Cronbach's $\alpha=0.894$ ).

The two questionnaires (demographic and ACQ) were completed by the participants.

The interventions were performed for ten sessions; 3 times a week for 15 min on each foot by a massage therapist. One day after completion of the ten intervention sessions, the questionnaires were again completed. The data was analyzed by SPSS 16 software. A p-value $<0.05$ was considered statistically significant.

\section{Results}

Totally 45 patients participated in this study. The Mean \pm SD of the age of participants were $38.9 \pm 14.2$ in the control group, $39.1 \pm 12.9$ in reflexology group and $49.9 \pm 15.5$ in Olive group. There was no significant difference among three study groups in the case of age. $40 \%$ of people in Control group had a smoking history, and it was $50 \%$ for the $\mathrm{R}$ and $30.8 \%$ for the $\mathrm{O}$ group respectively, without any significant difference among three groups. Asthma family history was $45.5 \%, 66.7 \%$ and $38.5 \%$ in $\mathrm{C}, \mathrm{R}$ and $\mathrm{O}$ groups respectively.

There was also no statistical significant difference among three study groups before intervention in AC scores. Table 1 shows the scores of Asthma Control Dimensions among three groups on the first day (before intervention) and the last day. Patients in $\mathrm{C}$ group had not significant difference in their AC scores before and after the study. A significant difference was seen in AC scores for both of $\mathrm{R}$ and $\mathrm{F}$ groups before and after the study $(\mathrm{p}<0.01)$. Moreover, there was no significant difference between $\mathrm{F}$ and $\mathrm{R}$ groups in their $\mathrm{AC}$ scores at the end of the intervention.

Table 1. The scores of asthma control dimensions among the study groups

\begin{tabular}{lllllll}
\hline $\begin{array}{l}\text { Groups } \\
\text { Asthma Control Dimensions }\end{array}$ & $\begin{array}{l}\text { Control } \\
\text { First } \\
\text { Day }\end{array}$ & $\begin{array}{l}\text { Control } \\
\text { Last } \\
\text { Day }\end{array}$ & $\begin{array}{l}\text { Refloxology } \\
\text { First Day }\end{array}$ & $\begin{array}{l}\text { Reflexology } \\
\text { Last Day }\end{array}$ & $\begin{array}{l}\text { Foot } \\
\text { massage } \\
\text { First Day }\end{array}$ & $\begin{array}{l}\text { Foot } \\
\text { massage } \\
\text { Last Day }\end{array}$ \\
\hline $\begin{array}{l}\text { Waking up during night due to Asthma } \\
\text { over the past week }\end{array}$ & $3.1 \pm 1.5$ & $3.2 \pm 1.7$ & $3.1 \pm 1.6$ & $1.5 \pm 0.9$ & $3 \pm 1.4$ & $1.6 \pm 0.8$ \\
$\begin{array}{l}\text { the severity of symptoms in the } \\
\text { morning over the past week }\end{array}$ & $3.7 \pm 1.7$ & $3.6 \pm 1.4$ & $3.8 \pm 1.5$ & $2.3 \pm 1.4$ & $3.7 \pm 1.5$ & $2.2 \pm 1.5$ \\
$\begin{array}{l}\text { The level of activity limitation due to } \\
\text { Asthma over the past week }\end{array}$ & $3.1 \pm 1.6$ & $3 \pm 1.7$ & $3.2 \pm 1.4$ & $1.4 \pm 0.8$ & $3.1 \pm 1.9$ & $1.2 \pm 0.9$ \\
\hline $\begin{array}{l}\text { Breath shortness due to Asthma over } \\
\text { the past week }\end{array}$ & $2.8 \pm 1.4$ & $2.8 \pm 1.7$ & $2.9 \pm 1.3$ & $1.2 \pm 07$ & $2.9 \pm 1.4$ & $1.3 \pm 0.8$ \\
\hline $\begin{array}{l}\text { Wheezing due to asthma over the past } \\
\text { week }\end{array}$ & $2.9 \pm 1.25$ & $2.9 \pm 1.4$ & $3 \pm 1.4$ & $1.6 \pm 1$ & $3 \pm .1 .6$ & $1.5 \pm 0.9$ \\
\hline $\begin{array}{l}\text { the number inhales from short-acting } \\
\text { bronchodilator over the past week }\end{array}$ & $2.7 \pm 1.5$ & $2.7 \pm 1.6$ & $2.8 \pm 1.6$ & $1.7 \pm 0.5$ & $2.9 \pm 1.7$ & $1.6 \pm 0.7$ \\
\hline \begin{tabular}{l} 
AC-Total \\
\hline
\end{tabular} & $2.9 \pm 0.8$ & $3 \pm 1.2$ & $3 \pm 1.1$ & $1.9 \pm 0.8$ & $2.9 \pm 1.2$ & $1.8 \pm 0.9$ \\
\hline
\end{tabular}

\section{Discussion}

The study showed that foot reflexology and olive oil foot massage improved asthma control adequacy. These results are consistent with Nekooee et al. regarding the effect of 20 minutes daily massage on 44 children with asthma for one month (Nekooee et al., 2008). Massage in their study involved stroking and kneading motions on the face, head, neck, shoulders, arms, hands, legs, feet and back. They collected data by interview and spirometry measurements.They found that daily massage improved airway tonicity, decreased airway sensitivity, and provided better asthma management.

The results of the present study showed that statistical significant differences between asthma control adequacy 
before and after intervention for the reflexology and olive oil foot rub groups. Brygge et al. conducted a randomized controlled trial where patients aged 18- 60 years with asthma received ten sessions of reflexology for 45 min once a week (Brygge et al., 2001). They compared symptoms, medication, and morning peak flow before and after treatment. The results of their study showed that reflexology decreased the symptom in patients with bronchial asthma.

The results of the present study were contradictory to the results of a study by Steenkamp. She found conflicting evidence among 35 studies published over the course of eight years and stated that no statistically significant evidence was reported for the benefits of reflexology for asthma and other diseases (Steenkamp, 2009). She added that was clinical evidence on the use of reflexology to promote well-being and quality of life in adults with chronic disease.

The results of Hondras et al. who reviewed three randomized controlled trials (RCTs), is not in consistency with the results of our study. They found no sufficient evidence to support the use of manual therapies for patients with asthma, although only one of the three RCTs was related to reflexology (Hondras et al., 2005). Ernst et al. published a systematic review of trials on reflexology in 1997 and 2009 and reported that it was possible, even probable, that its perceived benefit is brought about by non-specific effects (Ernst, 2009b). They updated this systematic review in 2010 using new RCTs for reflexology and stated that of the 23 RCTs from which 14 failed to show that reflexology is an effective treatment, 8 RCTs suggested positive effects, and one result was unclear (Ernst et al., 2011).

A clinical trial by Mirmohammadali et al. compared the effects of massages with sunflower oil and sesame oil on the duration of crying and sleeping in 120 infants (Mirmohammadali et al., 2011). They stated that the rapid percutaneous absorption of sunflower oil through massage and by rubbing it on the skin of premature infants compensated for a deficiency in essential fatty acid in serum and its clinical complications. They showed that sesame oil massage significantly decreased crying time compared to sunflower oil massage and massage alone.

The results of the present study are that olive oil foot massage on the skin significantly decreased asthma symptoms. Jäger et al. examined percutaneous absorption of lavender essential oil (Jager et al., 1992). They showed that lavender oil penetrates in the skin, and after five minutes of massage, linalool and lynalyl acetate, two components of lavender oil, can be detected in the blood. Percutaneous absorption is the passage of a substance from the outside through the entire thickness of the skin and into circulation (Malkinson and Rothman, 1962). The unique properties of each oil effect body systems after absorption. When subcutaneous circulation increases, the oils will be absorbed more quickly. Massages and massage increase blood flow to the skin. This theory had been clinically studied by Mirmohammadali et al. (2011). Jager et al. (1992) to show that the use of vegetable oils during massage enhance its absorption from one area of the skin into the body to produce systemic results.

A comparison of mean rank of asthma control for the reflexology and olive oil foot rub groups showed that olive oil foot massage were more successful for adequacy of asthma control than reflexology. This may be caused by the intervention of the olive oil which was accompanied by the massage. Reznik et al. (2004) compared asthma morbidity in a group who rubbed on ointment and an albuterol group showed that subjects in the ointment group were less likely than subjects in the albuterol group to have made an ED (Emergency Department) visit during the previous 12 months or over their lifetimes. They reported that massage independently predicted a lower incidence of lifetime ED use. The effectiveness mechanism of the ointment in the Reznik et al. study was percutaneous absorption, as the efficiency of olive oil in the present study. Both of these studies show that rubbing the skin can be helpful when treating asthma. It should be noted that a review of the literature was not conducted for similar studies to compare the effect of reflexology and olive oil foot massage on asthma control. Massages and oil massage are common methods of CM (Complementary Medicine) used by asthmatics; however, evidence that supports the efficacy of $\mathrm{CM}$ therapies from well-designed clinical trials is limited (Mokhtar and Chan, 2006).

\section{Limitations}

The primary restriction in this study was that, because asthma is a multifactorial disease, control of all factors was difficult and sometimes impossible. For example, changes in climate occurred several times during the study. Some patients caught a cold during the study, which increased their asthma symptoms. Some patients experienced increased stress and anxiety outside the study environment that could not be controlled.

Administration of the questionnaire by the researcher is another limitation of the study that could influence its outcome. The researchers controlled or eliminated confounder variables, such as the effects of gender, of the use of different routine medications prescribed by different doctors, and of the communication of treatment methods by 
subjects in one group to participants in other groups. The final study, however, was unbiased and could be generalized to a larger population.

\section{Conclusion}

Asthma is chronic in nature; asthma patients record a high number of disability days, high medical expenses, and recurrent referrals to clinics. The multi-causal nature of asthma is associated with financial barriers and poor asthma control. Marino et al. indicated that physicians should discuss the use of CAM with their asthma patients and that CAM use was significantly higher among persons with financial difficulties. They found that asthma patients who use CAM recorded fewer doctor visits to treat asthma and fewer asthma-associated disability days (Marino \& Shen, 2006). Patients follow CM because they feel more empowered by it and more in control of their illness after disappointing experiences with conventional treatments and concern about the adverse effects of conventional medicine (Juniper et al., 2005).

The results of present study show that foot reflexology and olive oil foot massage increased the adequacy of asthma control. The use of these interventions in conjunction with routine medication provides a better outcome than routine medications alone. The results show that foot reflexology and olive oil foot massage three times a week improved the daily activities and decreased shortness of breath and wheeze in asthma patients. Patients can be trained to apply these techniques themselves, which improves self-management of asthma. Both therapies were effective treatments and their combination with traditional treatments improved asthma control of chemical treatment alone.

These interventions produced no specific complications for any participant. More studies are needed to the efficacy of using both interventions, to compare the results with specific drug treatments, and investigate the percutaneous absorption rate of olive oil and the effect of its absorption on asthma.

Further investigation is needed to determine the percutaneous absorption rate of olive oil and the effect of its absorption on inflammatory diseases such as asthma.

\section{Acknowledgments}

We would like to thank all the patients who participated in this study. We also thank the Vice Chancellor of Research at Tabriz University of Medical Sciences for the financial support for this project.

\section{Competing Interests Statement}

The authors declare that there is no conflict of interests regarding the publication of this paper.

\section{References}

Amoli, K. (1998). Bronchopulmonary disease in Iranian housewives chronically exposed to indoor smoke. European Respiratory Journal, 11, 659-663.

Beauchamp, G. K., Keast, R. S., Morel, D., Lin, J., Pika, J., Han, Q., ... Breslin, P. A. (2005). Phytochemistry: Ibuprofen-like activity in extra-virgin olive oil. Nature, 437, 45-46. http://dx.doi.org/10.1038/437045a

Botting, D. (1997). Review of literature on the effectiveness of reflexology. Complementary Therapies in Nursing and Midwifery, 3, 123-130. http://dx.doi.org/10.1016/S1353-6117(97)80012-1

Brygge, T., Heinig, J., Collins, P., Ronborg, S., Gehrchen, P., Hilden, J., ... Poulsen, L. K. (2001). Reflexology and bronchial asthma. Respiratory Medicine, 95, 173-179. http://dx.doi.org/10.1053/rmed.2000.0975

Ernst, E. (2009a). Is reflexology an effective intervention? A systematic review of randomised controlled trials. Med J Aust, 191, 263-266.

Ernst, E. (2009b). Massage therapy for cancer palliation and supportive care: A systematic review of randomised clinical trials. Supportive Care in Cancer, 17, 333-337. http://dx.doi.org/10.1007/s00520-008-0569-z

Ernst, E., Posadzki, P., \& Lee, M. S. (2011). Reflexology: An update of a systematic review of randomised clinical trials. Maturitas, 68, 116-120. http://dx.doi.org/10.1016/j.maturitas.2010.10.011

Gunnarsdottir, T. J., \& Jonsdottir, H. (2007). Does the experimental design capture the effects of complementary therapy? A study using reflexology for patients undergoing coronary artery bypass graft surgery. Journal of Clinical Nursing, 16, 777-785. http://dx.doi.org/10.1111/j.1365-2702.2006.01634.x

Hondras, M. A., Linde, K., \& Jones, A. P. (2005). Manual therapy for asthma. The Cochrane Library. http://dx.doi.org/10.1002/14651858.cd001002.pub2

Jager, W., Buchbauer, G., Jirovetz, L., \& Fritzer, M. (1992). Percutaneous absorption of lavender oil from massage oil. J Soc Cosmet Chem, 43, 49-54. 
Juniper, E. (2012). Asthma control questionnaire. Background, analysis and administration. Bonham, West Sussex, UK: QOL Technologies LTD.

Juniper, E. F., Gruffydd-Jones, K., Ward, S., \& Svensson, K. (2010). Asthma Control Questionnaire in children: Validation, measurement properties, interpretation. European Respiratory Journal, 36, 1410-1416. http://dx.doi.org/10.1183/09031936.00117509

Juniper, E. F., Svensson, K., Mörk, A.-C., \& Ståhl, E. (2005). Measurement properties and interpretation of three shortened versions of the asthma control questionnaire. Respiratory Medicine, 99, 553-558. http://dx.doi.org/10.1016/j.rmed.2004.10.008

Juniper, E., Guyatt, G., Ferrie, P., \& King, D. (1999). Development and validation of a questionnaire to measure asthma control. European Respiratory Journal, 14, 902-907. http://dx.doi.org/10.1034/j.1399-3003.1999. 14d29.x

Liang, H. L. (2005). Chinese Remedial Massage (Tui Na).

Malkinson, F. D., \& Rothman, S. (1962). Percutaneous absorption. Normale und Pathologische Physiologie der Haut I. Springer.

Marino, L. A., \& Shen, J. (2006). Characteristics of complementary and alternative medicine use among adults with current asthma, 2006. Journal of Asthma, 47, 521-525. http://dx.doi.org/10.3109/02770900903576320

Masoli, M., Fabian, D., Holt, S., \& Beasley, R. (2004). The global burden of asthma: Executive summary of the GINA Dissemination Committee report. Allergy, 59, 469-478. http://dx.doi.org/10.1111/j.1398-9995. 2004.00526.x

Mathew, J., Aronow, W. S., \& Chandy, D. (2012). State of the art paper Therapeutic options for severe asthma. Archives of Medical Science, 8, 589. http://dx.doi.org/10.5114/aoms.2012.30280

Mirmohammadali, M., Golian Tehrani, S., Kazemnejad, A., Hosseini Baharanchi, F. S., Minaee, B., Bekhradi, R., \& Raisi Dehkordi, Z. (2011). A Comparative Study of the Effect of Massage with Sunflower Oil or Sesame Oil on Infants' Crying and Sleep Times: A Randomized Clinical Trial. Hayat, 17, 80-90.

Mokhtar, N., \& Chan, S. (2006). Use of complementary medicine amongst asthmatic patients in primary care. Med J Malaysia, 61, 125-127.

Nakamaru, T., Miura, N., Fukushima, A., \& Kawashima, R. (2008). Somatotopical relationships between cortical activity and reflex areas in reflexology: A functional magnetic resonance imaging study. Neuroscience letters, 448, 6-9. http://dx.doi.org/10.1016/j.neulet.2008.10.022

Nekooee, A., Faghihinia, J., Ghasemy, R., Ghaibizadeh, M., \& Ghazavi, Z. (2008). Effect of massage therapy on children with asthma. Iranian Journal of Pediatrics, 18, 123-129.

Qamar, N., Pappalardo, A. A., Arora, V. M., \& Press, V. G. (2011). Patient-centered care and its effect on outcomes in the treatment of asthma. Patient Related Outcome Measures, 2, 81.

Reddel, H. K., Taylor, D. R., Bateman, E. D., Boulet, L.-P., Boushey, H. A., Busse, W. W., ... Gibson, P. G. (2009). An official American Thoracic Society/European Respiratory Society statement: Asthma control and exacerbations: standardizing endpoints for clinical asthma trials and clinical practice. American Journal of Respiratory and Critical Care Medicine, 180, 59-99. http://dx.doi.org/10.1164/rccm.200801-060ST

Reznik, M., Ozuah, P. O., Franco, K., Cohen, R., \& Motlow, F. (2002). Use of complementary therapy by adolescents with asthma. Archives of Pediatrics \& Adolescent Medicine, 156, 1042-1044. http://dx.doi.org/10.1001/archpedi.156.10.1042

Reznik, M., Sharif, I., \& Ozuah, P. O. (2004). Rubbing ointments and asthma morbidity in adolescents. Journal of Alternative \& Complementary Medicine, 10, 1097-1099. http://dx.doi.org/10.1089/acm.2004.10.1097

Sarmad, Z., Bazarghan, A., \& Hejazie, E. (2014). Research Methods in Behavioral Sciences. Tehran, Iran, Agha.

Sorcinelli, P. (1997). In J. Flandrin, \& M. Montanari (Eds.), Storia Dell'alimentazione. Laterza, Roma-Bari (Italy).

Steenkamp, E. (2009). An integrative literature review of the utilisation of reflexology in adults with chronic disease. North-West University.

The American Heritage Dictionary of the English Language. Houghton Mifflin Harcourt. Retrieved 2009, from http://www.thefreedictionary.com/ 
Voner, V. (2003). The Everything Reflexology Book. Avon, MA: Adams Media Corp.

Wang, M. Y., Tsai, P. S., Lee, P. H., Chang, W. Y., \& Yang, C. M. (2008). The efficacy of reflexology: Systematic review. Journal of Advanced Nursing, 62, 512-520. http://dx.doi.org/10.1111/j.1365-2648. 2008.04606.x

Weiss, W., Vogelmeier, C., \& Görg, A. (1993). Electrophoretic characterization of wheat grain allergens from different cultivars involved in bakers' asthma. Electrophoresis, 14, 805-816. http://dx.doi.org/10.1002/elps. 11501401126

WHO. (2014). Asthma prevalence. Cairo: Regional Office for the Eastern Mediterranean. Retrieved June 9, 2014, from http://www.emro.who.int/health-topics/asthma/index.html

\section{Copyrights}

Copyright for this article is retained by the author(s), with first publication rights granted to the journal.

This is an open-access article distributed under the terms and conditions of the Creative Commons Attribution license (http://creativecommons.org/licenses/by/3.0/). 